NASA/TM-2004-212964

\title{
Ice Particle Impact on Cloud Water Content Instrumentation
}

Edward F. Emery, Dean R. Miller, and Stephen R. Plaskon

Glenn Research Center, Cleveland, Ohio

Walter Strapp

Meteorological Services of Canada, Downsview, Ontario

Lyle Lillie

Science Engineering Associates, Inc., Mansfield Center, Connecticut 
Since its founding, NASA has been dedicated to the advancement of aeronautics and space science. The NASA Scientific and Technical Information (STI) Program Office plays a key part in helping NASA maintain this important role.

The NASA STI Program Office is operated by Langley Research Center, the Lead Center for NASA's scientific and technical information. The NASA STI Program Office provides access to the NASA STI Database, the largest collection of aeronautical and space science STI in the world. The Program Office is also NASA's institutional mechanism for disseminating the results of its research and development activities. These results are published by NASA in the NASA STI Report Series, which includes the following report types:

- TECHNICAL PUBLICATION. Reports of completed research or a major significant phase of research that present the results of NASA programs and include extensive data or theoretical analysis. Includes compilations of significant scientific and technical data and information deemed to be of continuing reference value. NASA's counterpart of peerreviewed formal professional papers but has less stringent limitations on manuscript length and extent of graphic presentations.

- TECHNICAL MEMORANDUM. Scientific and technical findings that are preliminary or of specialized interest, e.g., quick release reports, working papers, and bibliographies that contain minimal annotation. Does not contain extensive analysis.

- CONTRACTOR REPORT. Scientific and technical findings by NASA-sponsored contractors and grantees.
- CONFERENCE PUBLICATION. Collected papers from scientific and technical conferences, symposia, seminars, or other meetings sponsored or cosponsored by NASA.

- SPECIAL PUBLICATION. Scientific, technical, or historical information from NASA programs, projects, and missions, often concerned with subjects having substantial public interest.

- TECHNICAL TRANSLATION. Englishlanguage translations of foreign scientific and technical material pertinent to NASA's mission.

Specialized services that complement the STI Program Office's diverse offerings include creating custom thesauri, building customized databases, organizing and publishing research results ... even providing videos.

For more information about the NASA STI Program Office, see the following:

- Access the NASA STI Program Home Page at http://www.sti.nasa.gov

- E-mail your question via the Internet to help@sti.nasa.gov

- Fax your question to the NASA Access Help Desk at 301-621-0134

- Telephone the NASA Access Help Desk at 301-621-0390

- Write to:

NASA Access Help Desk

NASA Center for AeroSpace Information 7121 Standard Drive

Hanover, MD 21076 
NASA/TM-2004-212964

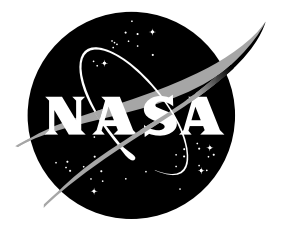

\section{Ice Particle Impact on Cloud Water Content Instrumentation}

Edward F. Emery, Dean R. Miller, and Stephen R. Plaskon

Glenn Research Center, Cleveland, Ohio

Walter Strapp

Meteorological Services of Canada, Downsview, Ontario

Lyle Lillie

Science Engineering Associates, Inc., Mansfield Center, Connecticut

Prepared for the

42nd Aerospace Sciences Meeting and Exhibit

sponsored by the American Institute of Aeronautics and Astronautics

Reno, Nevada, January 5-8, 2004

National Aeronautics and

Space Administration

Glenn Research Center 


\section{Acknowledgments}

The authors would like to acknowledge and thank the staff of Cox \& Company, and in particular

Dr. Kamel Al-Khalil and Dr. Eddie Irani for their support during testing conducted at the Cox \& Company LeClerc Icing Research Laboratory. The authors would also like to thank the Imaging Technology Center, NASA Glenn

Research Center, for their expertise in high speed close up imaging techniques, and their invaluable assistance with this experimental effort.

This report contains preliminary

findings, subject to revision as analysis proceeds.

Available from

NASA Center for Aerospace Information 7121 Standard Drive

Hanover, MD 21076
National Technical Information Service 5285 Port Royal Road Springfield, VA 22100 


\title{
ICE PARTICLE IMPACT ON CLOUD WATER CONTENT INSTRUMENTATION
}

\author{
Edward F. Emery, ${ }^{*}$ Dean R. Miller, ${ }^{\dagger}$ and Stephen R. Plaskon \\ National Aeronautics and Space Administration \\ Glenn Research Center \\ Cleveland, Ohio \\ Walter Strapp ${ }^{\S}$ \\ Meteorological Services of Canada \\ Downsview, Ontario \\ Lyle Lillie ${ }^{* *}$ \\ Science Engineering Associates, Inc. \\ Mansfield Center, Connecticut
}

\begin{abstract}
Determining the total amount of water contained in an icing cloud necessitates the measurement of both the liquid droplets and ice particles. One commonly accepted method for measuring cloud water content utilizes a hot wire sensing element, which is maintained at a constant temperature. In this approach, the cloud water content is equated with the power required to keep the sense element at a constant temperature. This method inherently assumes that impinging cloud particles remain on the sensing element surface long enough to be evaporated.
\end{abstract}

In the case of ice particles, this assumption requires that the particles do not bounce off the surface after impact. Recent tests aimed at characterizing ice particle impact on a thermally heated wing section, have raised questions about the validity of this assumption. Ice particles were observed to bounce off the heated wing section a very high percentage of the time. This result could have implications for Total Water Content sensors which are designed to capture ice particles, and thus do not account for bouncing or breakup of ice particles.

Based on these results, a test was conducted to investigate ice particle impact on the sensing elements of the following hot-wire cloud water content probes: (1) Nevzorov Total Water Content (TWC)/Liquid Water Content (LWC) probe, (2) Science Engineering

\footnotetext{
* AIAA member, Flight Research Engineer

† AIAA member, Icing Research Engineer

+ Flight Research Avionics Technician

$\S$ Cloud Research Physicist

** President
}

Associates TWC probe, and (3) Particle Measuring Systems King probe. Close-up video imaging was used to study ice particle impact on the sensing element of each probe. The measured water content from each probe was also determined for each cloud condition.

This paper will present results from this investigation and attempt to evaluate the significance of ice particle impact on hot-wire cloud water content measurements.

\section{NOMENCLATURE}

FAA Federal Aviation Administration

IWC ice water content $\left(\mathrm{g} / \mathrm{m}^{3}\right)$

LWC liquid water content $\left(\mathrm{g} / \mathrm{m}^{3}\right)$

TWC total water content (LWC + IWC)

MVD median volumetric diameter $(\mu \mathrm{m})$

NASA National Aeronautics and Space Administration

\section{INTRODUCTION}

The motivation for conducting this experimental investigation began as a result of NASA's participation in a test to evaluate the effect of mixed phase icing conditions on thermal ice protection system power requirements. This test was sponsored by the FAA, and was a collaborative activity between Cox \& Company, NASA Glenn Research Center, and Wichita State University. Two objectives for this test were: (1) to determine how thermal power requirements for mixed phase conditions would compare with those for liquid only conditions, and (2) to investigate the degree to which ice particles "stick" or "bounce" upon impacting a surface. This test was conducted in the Cox \& Company LeClerc Icing Research Laboratory wind tunnel. ${ }^{1}$ 


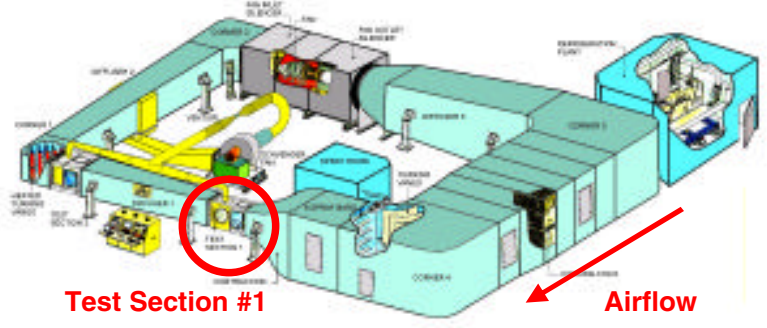

Figure 1. Cox \& Company icing wind tunnel.

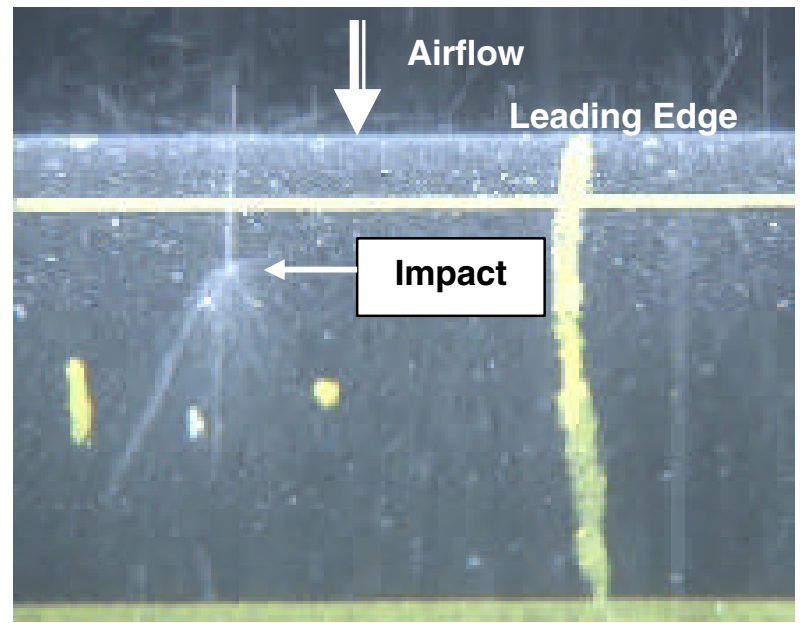

Figure 2. Typical ice particle impact on unheated airfoil surface in mixed phase icing test conducted at Cox \& Company icing wind tunnel in 2002.

A test article consisting of a 2-D wing section with an electro-thermal ice protection system was tested under a variety of mixed phase conditions. NASA Glenn provided high-speed close-up imaging systems for this test. The visual information obtained from the imaging systems was intended to complement thermal measurements from the test article.

During the mixed phase icing test, ice particles and fragments (resulting from impact) were observed to "bounce" off the test article surface. Figure 2 shows high definition camera imagery of a large ice particle impact on an unheated surface, along with many other smaller ice particle impacts.

Bouncing of ice particles (or fragments) was observed for every simulated mixed phase icing condition, regardless of the whether the surface was heated or unheated, dry or wet. The frequency with which "bouncing" was observed, caused us to speculate that ice particles might also be "bouncing" upon impact with hot-wire Total Water Content (TWC) sensors. Since TWC probes have been assumed to capture and evaporate all impinging particles (whether ice or super- cooled liquid), we then wondered how "bouncing" of ice particles might affect "indicated" ice water content (IWC) measurements. If the ice particles (or their fragments) were not remaining on the sensor surface, it would be reasonable to assume that the indicated IWC might be lower than the actual IWC.

To investigate this further, a test was conducted in the LeClerc Icing Research Laboratory wind tunnel in June 2003. Hotwire LWC and TWC probes were subjected to a range of icing conditions having both liquid and ice particles. The measurements from these instruments were then inter-compared with each other. As with the previous mixed phase test, high-speed close-up imaging was used to study the impact of ice particles on the hotwire sensing elements of several probes. The test objectives were as follows:

- Determine if ice particles "bounce-off" sensing elements of hot-wire probes

- If bouncing occurs, attempt to quantify the effect of bouncing on measured liquid water content

- Inter-compare the response of hot-wire probes subjected to mixed phase icing conditions in a controlled environment

\section{EXPERIMENTAL SETUP}

Test section \#1 of the Cox \& Company wind tunnel was used for this investigation. The test section dimensions were 28 inches $(0.71 \mathrm{~m})$ wide by 46 inches high $(1.17 \mathrm{~m})$.

A special floor plate and mounting stand assembly was fabricated to allow the sampling area of each probe sensor to be physically mounted at the same location in 3-D space. The floor plate was drilled with holes to facilitate mounting of custom hot-wire and particle sizing probe support stands. These custom fabricated stands, compensated for the unique geometry of each probe, and placed them at the desired position (vertical center of the tunnel, and within 1.5 inches $(3 \mathrm{~cm})$ off the horizontal center of the tunnel). This was done to minimize water content measurement errors due to position.

A Nevzorov water content probe was mounted from the test section ceiling, to provide a "reference" water content measurement. This measurement was intended to provide an estimate of the variability in icing tunnel conditions during a run and also from run to run. It was labeled the "reference" Nevzorov probe, and it was located 5.5 inches $(13.8 \mathrm{~cm})$ directly above the device under test. This vertical offset distance represented a compromise between trying to get the "reference" and "test" probes as close as possible, yet still maintain enough separation from the probe "test" position. This 


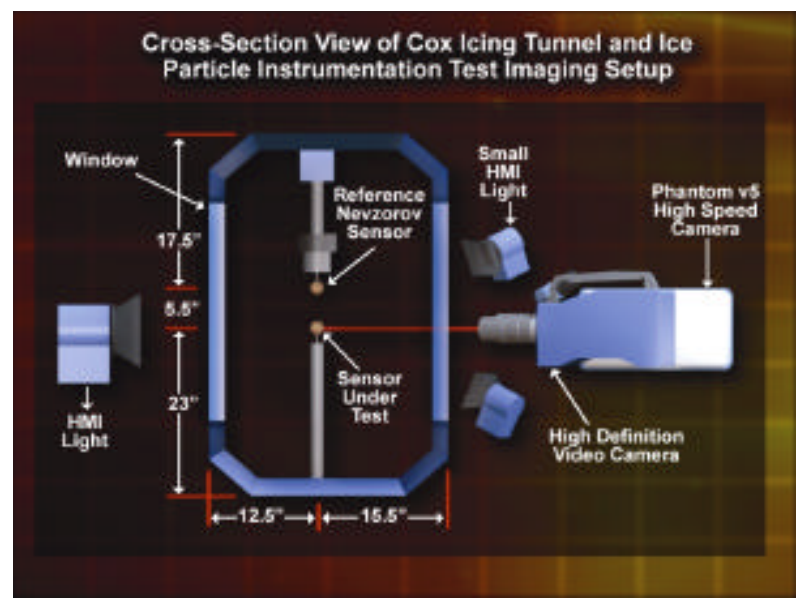

Figure 3. Cross-sectional view of test section \#1, showing "reference" Nevzorov probe and water content instrument "test" location (note: airflow into the paper).

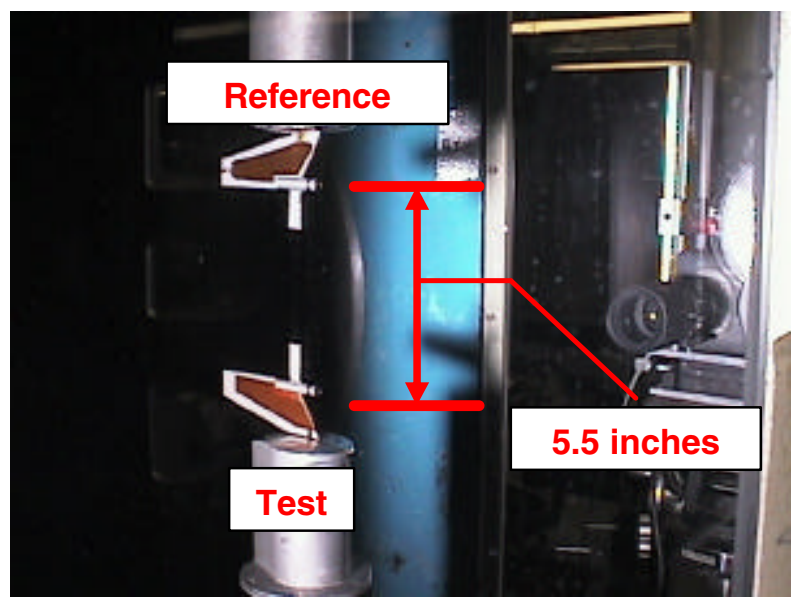

Figure 4. Side view looking into test section \#1 with Nevzorov probe mounted in the "test" position.

offset distance had to account for not only the vertical height of the water content probes which were tested there, but also the FSSP and OAP 2Dgrey probes which were used to characterize the particle size distributions of the icing cloud.

The vertical and horizontal dimensions of the "test" position and "reference" Nevzorov position within the tunnel cross-section are illustrated in Figure 3. Figure 4 shows a Nevzorov probe mounted in the "test" position, and illustrates the 5.5 inch vertical offset between the center of each TWC sensor
Water Content Probes Tested

Several different hotwire water content probes were evaluated for their response to ice particles during this test: (1) Nevzorov TWC/LWC probe, (2) Science Engineering Associates TWC probe, and (3) King LWC probe.

The Nevzorov probe (Figure 5) has both a TWC sensor and an LWC sensor integrated into one vane. ${ }^{2}$ This feature enables it not only to measure the Total Water Content (Liquid + Ice), but to provide an estimate of Ice Water Content (IWC) in mixed phase conditions. Though water content measurements were recorded from both sensors, the imaging equipment was focused only on the conical TWC sensing element.

Another TWC probe, developed by Science Engineering Associates (SEA), was evaluated for its response to ice particles. Normally this probe has an annular shroud surrounding the half-cylindrical shaped sensing element. However, the shroud was removed to facilitate lighting and viewing of the sense element for this test. Figure 6 a shows the SEA TWC probe with the shroud, while Figure $6 \mathrm{~b}$ shows just the sensing element with the shroud removed.

A King LWC probe (Figure 7) was also evaluated for its response to ice particles. The imaging equipment was focused on the sensing wire, which extended between the two horizontal support arms. The King probe was included in this test because it has been used extensively as a reliable liquid water content measurement device over the years, resulting in a large database to characterize its performance. Therefore, it was thought that King probe results from this test might be compared with this body of existing data.

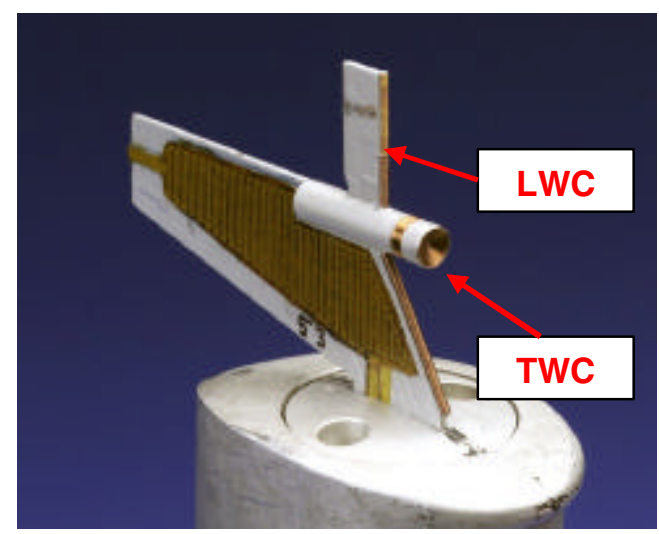

Figure 5. Nevzorov TWC/LWC probe. 


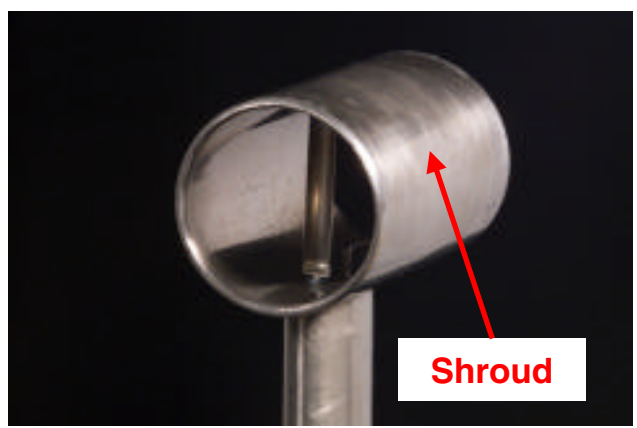

6a. SEA total water content probe.

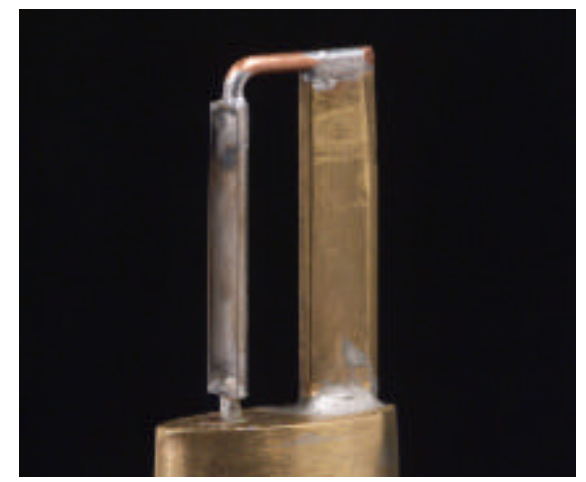

6b. SEA TWC probe (shroud removed).

Figure 6. Science Engineering Assoc. TWC probe.

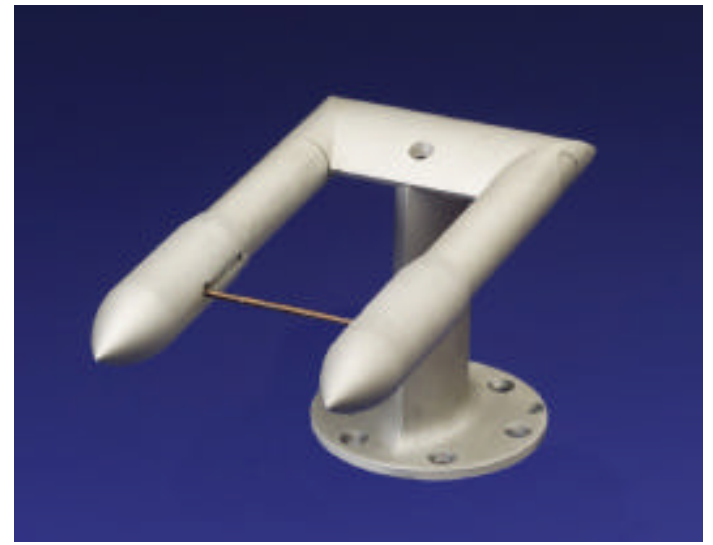

Figure 7. King LWC probe.

\section{Imaging System}

The imaging systems utilized in this test were selected based on their previous usage in the Mixed Phase icing test. ${ }^{1}$ A High Definition (HD) video camera (Figure 8), and a Phantom v5 high frame rate camera (Figure 9) were used to visually study the impact of ice particles on the sensing element of the hot-wire cloud water content probes.

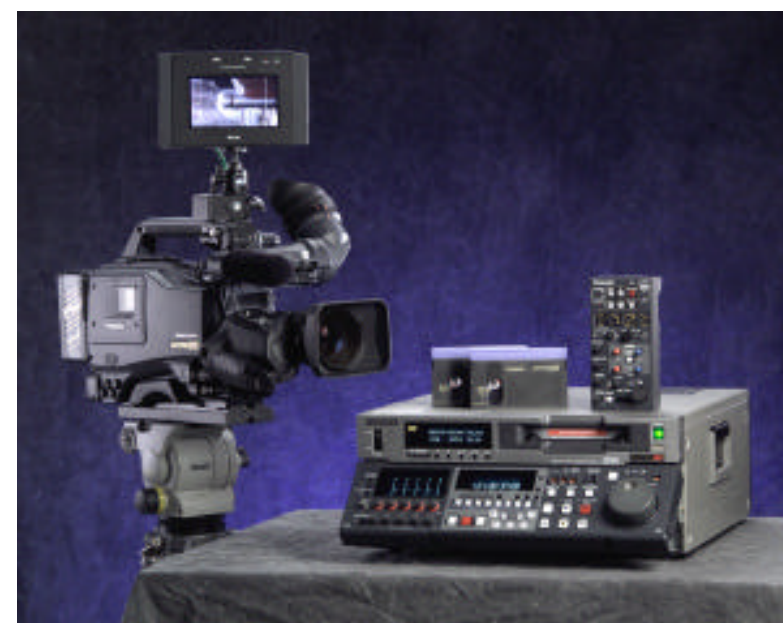

Figure 8. High-Definition (HD) camera system.

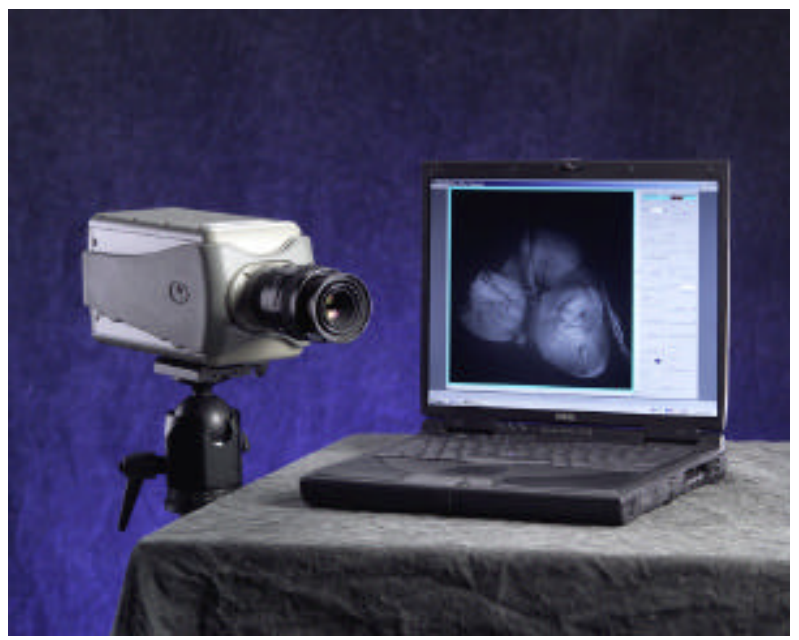

Figure 9. Phantom v5 high frame rate camera.

The HD video camera was intended to provide a realtime high resolution record of each test run. The highframe rate camera was intended to capture ice particle impact at high speed, to facilitate later playback at reduced speeds.

Imaging and lighting of the instruments under test were accomplished using the side windows of test section \#1. The HD camera, and the high frame rate camera were placed on the inner side of the tunnel loop, along with some small HMI lights. A larger HMI light was positioned in the opposite side window to provide back illumination of the test article for the high frame rate camera. Figure 10 shows a top view of the setup. 


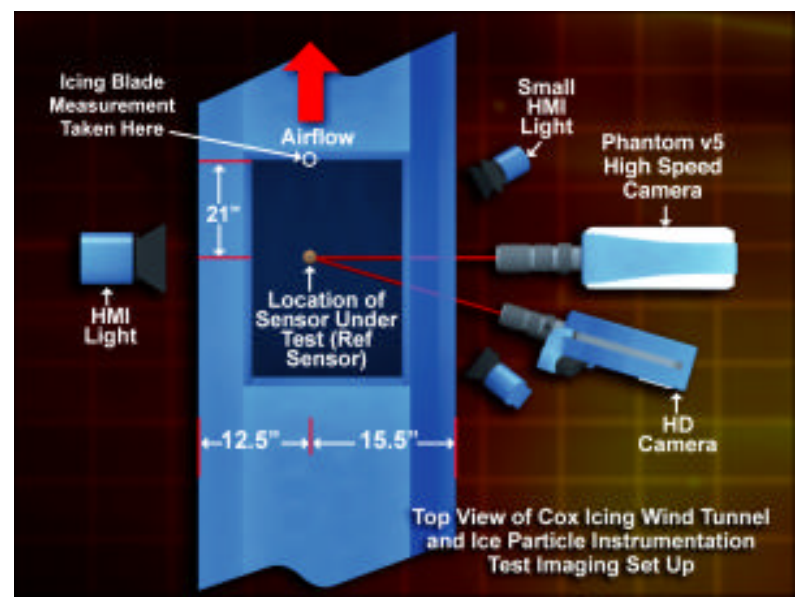

Figure 10. Imaging setup for investigation of ice particle impact on cloud water content instrumentation.

Table I. Range of test conditions used to evaluate hotwire probe response to ice particles (note: supercooled water spray had approximately $30 \mu \mathrm{m}$ MVD).

\begin{tabular}{|l|c|c|c|c|}
\hline $\begin{array}{c}\text { Condition/ } \\
(\text { Setting) }\end{array}$ & $\begin{array}{c}\text { LWC, } \\
\left(\mathbf{g} / \mathbf{m}^{\mathbf{3}}\right)\end{array}$ & $\begin{array}{c}\text { IWC } \\
\text { level }\end{array}$ & $\begin{array}{c}\text { Ttot, } \\
\left({ }^{\circ} \mathbf{C}\right)\end{array}$ & $\begin{array}{c}\mathbf{V}, \\
(\mathbf{m p s})\end{array}$ \\
\hline spray 1 & 0.48 & -- & -12.2 & 67 \\
\hline spray 2 & 0.70 & -- & -12.2 & 67 \\
\hline spray 3 & 0.97 & -- & -12.2 & 67 \\
\hline shaver 1 (161) & -- & $\begin{array}{c}\text { very } \\
\text { low }\end{array}$ & -12.2 & 67 \\
\hline shaver 2/(81) & -- & low & -12.2 & 67 \\
\hline shaver 3/(41) & -- & med & -12.2 & 67 \\
\hline shaver 4/(31) & -- & high & -12.2 & 67 \\
\hline mixed & 0.48 & med & -12.2 & 67 \\
\hline
\end{tabular}

\section{Test Process}

To evaluate the effect of ice particles on hot-wire probe measurements, the test article was subjected to a range of conditions including super-cooled water $(100 \%$ liquid), a mixture of ice particles and liquid, and all ice particles (100\% ice). Water content measurements and close-up video of the probe sensing elements were acquired for each of these test conditions which are listed in Table I.

The super-cooled water conditions were included to allow comparison of hot-wire water content measurements with icing blade measurements. This provided a "baseline" measurement of probe performance relative to a reference measurement. Unfortunately, no such reference was available for the ice phase conditions.

Four "all ice" conditions were generated using the Cox \& Company's ice shaver system. The relative IWC levels are shown in Table I. These relative levels were established based on Cox \& Company's previous experience with the ice shaver. Measured values of IWC will be presented for these conditions later in this report. There was also one mixed phase test condition comprised of super-cooled spray, and ice shaver particles. However, only the results for the all liquid and all ice conditions will be discussed in this report. Analysis of mixed-phase results had not been completed at the time this report was being written.

\section{IMAGING RESULTS}

Ice particles were observed to impact the hot-wire sensing element of the probes. In some cases the ice particles shattered into multiple smaller fragments, some of which rebounded off the sensor surface into the air-stream and were swept away. In other cases, the ice particle impact was observed to splash liquid off the sensing element and into the air-stream where it was swept away. Typical high-frame rate camera imagery of ice particle impacts are shown in Figures 11 and 12 for the SEA TWC sensor, and the King probe sense wire, respectively.

One of the goals of this experimental effort was to estimate to what degree the "bouncing" of ice particles might affect water content measurements. A very simple approach was tried using high-frame rate camera imagery, whereby over a certain time period, the incoming particles and rebounding particles would be counted. After trying to implement this approach on several time periods of imagery, it became clear that this approach was impractical. Thus, we were not able to estimate the "degree of bouncing" and correlate it with a specific sensor, using visual imaging data. We plan to investigate other potential methods to estimate the "degree of bouncing" for use with the currently acquired data, and possibly for future tests.

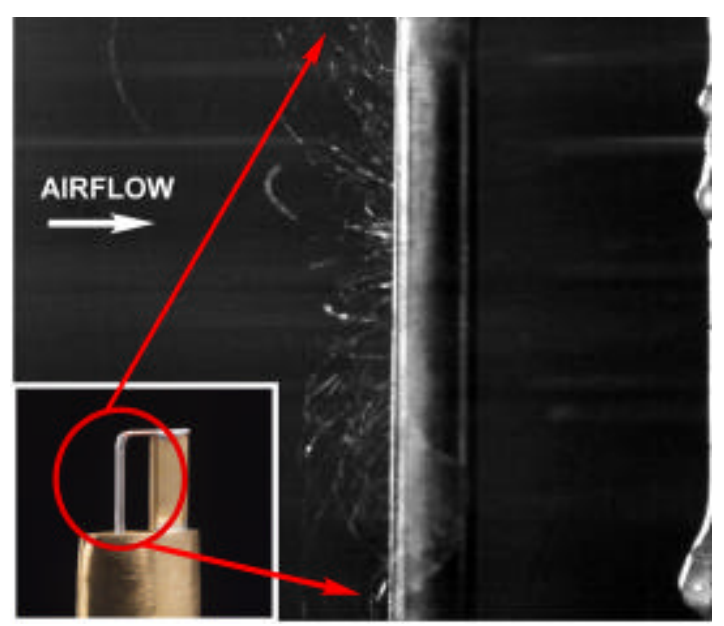

Figure 11. Ice particle impact on Science Engineering Associates TWC hot-wire sensing element (halfcylinder cross section). 


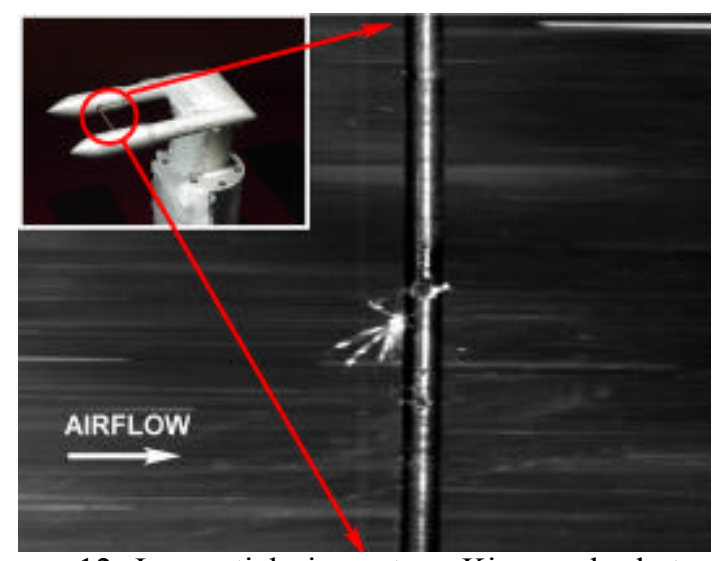

Figure 12. Ice particle impact on King probe hot-wire sensing element (cylindrical cross section).

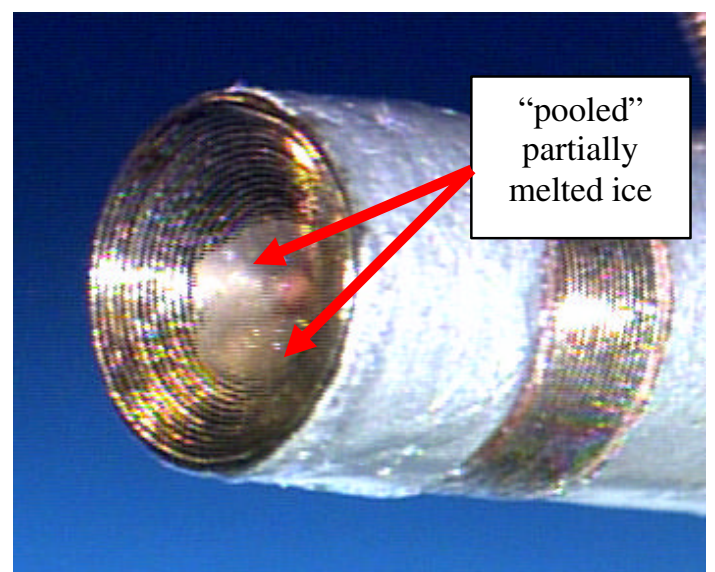

Figure 13. Close-up of Nevzorov TWC hot-wire sensing element showing melted ice particles.

One unexpected result was a phenomena we called "pooling". It was first noticed occurring on the Nevzorov TWC sensor, and post-test review of high frame rate camera imagery suggests it may also be occurring on the SEA TWC sensor (to some degree). This phenomenon was manifest as a buildup of what appeared to be a slushy "pooled" mass of partially melted ice particles, as shown in Figure 13.

This mass appeared to grow in size, and at some point was eventually ejected from the sensing cone element, whereupon the cycle would start again.

Figure 14 shows a sequence of images from the high frame rate camera where material appears to be forced out of the Nevzorov TWC cone. The icing condition for this set of images was "ice shaver 3". There appears to be an initial impact of a relatively large ice particle followed, by the expulsion of material (probably water
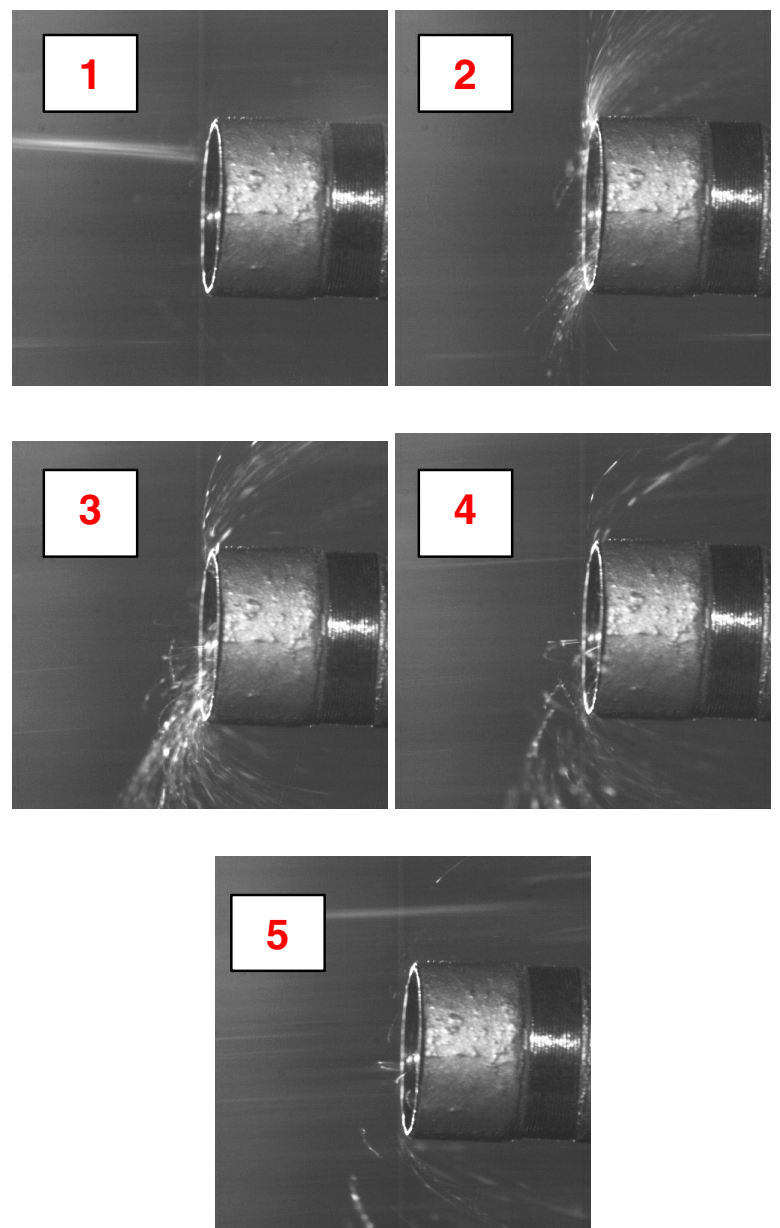

Figure 14. Sequence of high frame rate camera images showing expulsion of material from the Nevzorov TWC.

and ice). Unfortunately we did not have all our cameras "time-code synchronized" to precisely correlate this imagery with the HD video, but we believe the image sequence in Figure 14 to be representative of the ejection portion of the "pooling" phenomenon.

Review of HD video imagery seems to suggest that "pooling" may be related to the IWC level. It was observed at ice shaver levels 3 and 4, but not at ice shaver level 1 (based on the limited number of runs we conducted). Examination of video just prior to the start of "pooling", reveals water rivulets on the surface of the sensing cone wires. The water appears to run radially out of the cone, probably in a symmetrical fashion. Then at some time after this, the slushy ice mass begins to build, starting at the center of the cone, then expanding outward. Sometime after this, it appeared to be expelled from the cone by aerodynamic forces. 
We attempted to vary the sensor wire operating temperature to see if it had an effect on "pooling". Test runs were conducted with the wire operating temperature set at 70, 90, and $120{ }^{\circ} \mathrm{C}$. "Pooling" was observed for each operating temperature, thus it appeared that the operating temperature did not affect "pooling" as significantly as IWC level.

However, HD video imagery of the TWC cone did reveal some differences between the different operating temperature cases. Contrary to what we expected, the $120{ }^{\circ} \mathrm{C}$ case actually seemed to increase the frequency at which the "pooling" occurred, rather than eliminate it. At the $70{ }^{\circ} \mathrm{C}$ temperature, there appeared to be more water on the surface of the cone, than at the other operating temperatures. Since the above operating temperature test runs were conducted at the highest IWC (shaver 4 condition), it is possible that the higher IWC level may have masked details related to operating temperature variations. Thus, we believe additional testing is required at lower IWC levels to accurately characterize the effect of operating temperature on the occurrence of "pooling".

\section{WATER CONTENT MEASUREMENT RESULTS}

Water content measurements were obtained in conjunction with the close-up imaging data described in the previous section. This section will present some of the more significant results. At time of this writing, the mixed phase test results had not been analyzed, thus only results from all liquid or all ice test conditions will be discussed.

$\underline{\text { Icing Blade Calibration }}$

It was recognized that a comparison with a reference measurement (such as the icing blade) was needed to characterize the hot-wire probes response under known conditions. Therefore, icing blade measurements were obtained for each of the three super-cooled liquid spray conditions. The icing blade measurements were obtained at a total temperature of $0{ }^{\circ} \mathrm{F}\left(-17.8^{\circ} \mathrm{C}\right)$, to ensure that the rime ice was accreted on the Cox \& Company icing blade (shown in Figure 15).

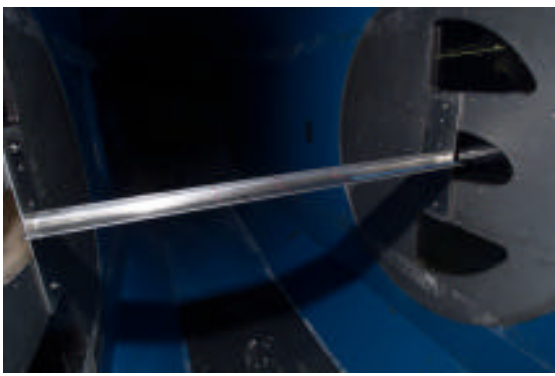

Figure 15. Icing blade installed in test section \#1.
The icing blade was positioned at the vertical centerline of the tunnel, and the leading edge of the blade was about 18 inches $(0.46 \mathrm{~m})$ behind the test location.

Icing blade measurements were obtained using two methods. The first method was the traditional method where the thickness of ice on the blade was measured and used to compute LWC. The second method involved measuring the mass of ice accreted on the blade over a span of about an inch $(2.5 \mathrm{~cm})$, and then determining the LWC. Both methods yielded similar results, which are shown in Table II for the three supercooled spray conditions. The MVD determined from the FSSP and OAP-2D grey probe measurements is also included for each spray condition.

An FSSP and an OAP-2Dgrey probe were used to characterize the droplet size distribution of the supercooled sprays. A drop size spectrum is shown in Figure 16 for spray 1 condition.

Table II. Icing blade LWC.

\begin{tabular}{|l|c|c|c|}
\hline Condition & $\begin{array}{c}\text { LWC } \\
\text { thickness } \\
\text { method } \\
\left(\mathbf{g} / \mathbf{m}^{\mathbf{3}}\right)\end{array}$ & $\begin{array}{c}\text { LWC } \\
\mathbf{m a s s} \\
\mathbf{m e t h o d} \\
\left(\mathbf{g} / \mathbf{m}^{\mathbf{3}}\right)\end{array}$ & $\begin{array}{c}\text { MVD } \\
(\boldsymbol{\mu m})\end{array}$ \\
\hline Spray 1 & 0.48 & 0.49 & 28 \\
\hline Spray 2 & 0.71 & 0.74 & 30 \\
\hline Spray 3 & 0.97 & 1.05 & 31 \\
\hline
\end{tabular}

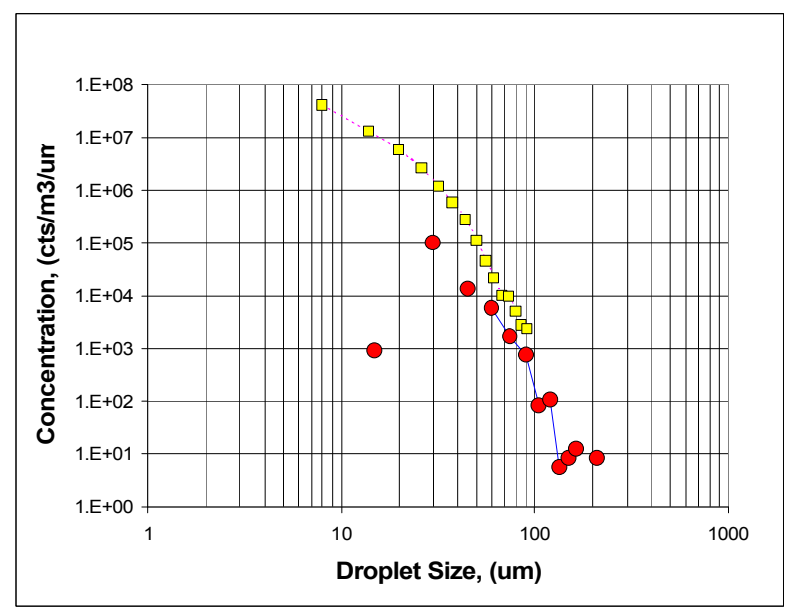

Figure 16. Drop size spectra for super-cooled spray 1 condition. 


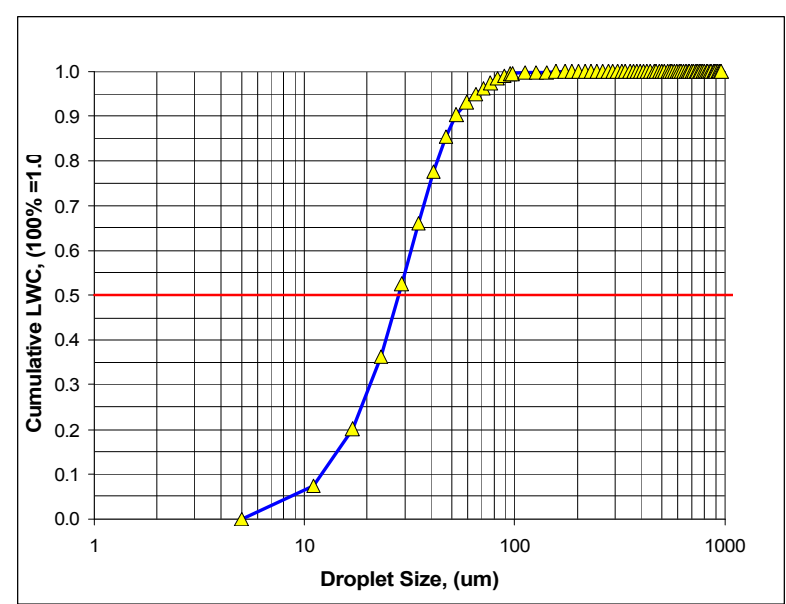

Figure 17. Normalized cumulative LWC for supercooled spray 1 condition.

The shape of the distribution is considered representative of the other two super-cooled liquid spray conditions. For illustration purposes, the 2Dgrey data are shown overlapped with the FSSP data in Figure 16 , but the combined spectra were formed by using all the FSSP bins (squares) and dropping the first 6 bins of the 2Dgrey probe (circles). The usual activity corrections were applied to the FSSP bin data. The normalized cumulative LWC is shown in Figure 17 for the spray 1 condition. The MVD determined from the combined spectra for the three super-cooled spray conditions are listed in Table II.

\section{Icing Condition Variability}

When we were planning this test, we felt it was important to have an independent measurement that could provide us with an estimate of variability in the icing tunnel conditions. This was based on our previous experience in the mixed phase icing tests in 2002, where we observed the ice shaver conditions to have more variability than the super-cooled liquid spray conditions. Thus if we were attempting to identify significant changes in sensor output as a function of different ice shaver conditions, we would need to account for the variability inherent in each condition.

Our plan to address this issue resulted in the decision to install a second Nevzorov sensor as close as practical to the "test" location. This second Nevzorov probe we labeled the "reference" sensor, because it was used as an independent method to estimate the uncertainty inherent in icing conditions at the "test" position. It was located in close proximity (5.5 inches) directly above the "test" position, thus it was reasonable to assume that it was exposed to icing conditions which were representative of the "test" position. Since the reference

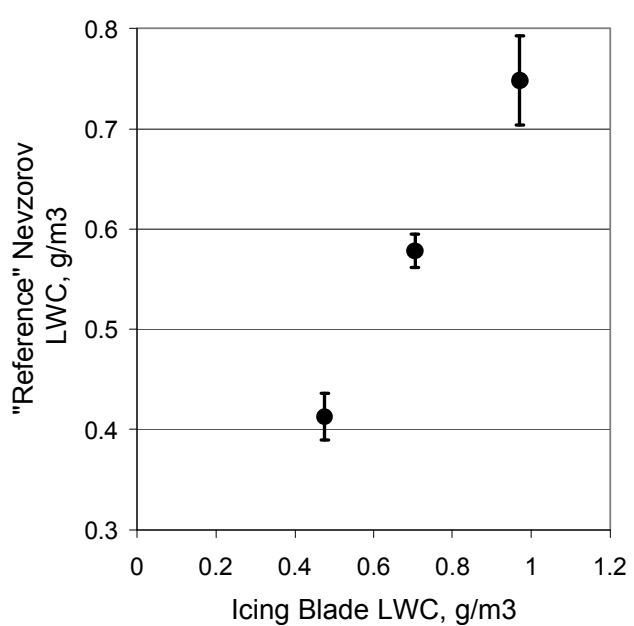

Figure 18. LWC measurement variability.

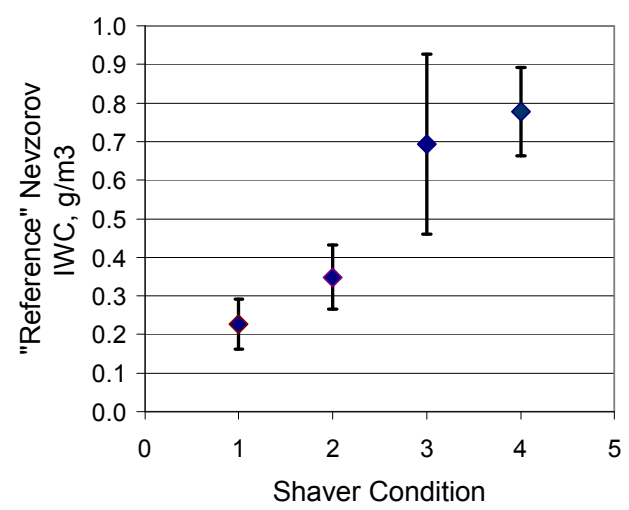

Figure 19. Ice shaver condition variability.

sensor remained in the tunnel for the duration of the test, it was possible to acquire multiple runs for each icing condition with which to estimate icing condition variability.

The variability in super-cooled liquid conditions is shown as measured by the "reference" Nevzorov LWC sensor in Figure 18. The variability is shown by the error bars, which reflect one standard deviation about the mean value (marker). It can be seen that the variability was somewhat greater for the highest LWC condition.

The variability in ice shaver conditions as measured by the "reference" Nevzorov TWC sensor is shown in Figure 19. A comparison between Figures 18 and 19, reveals that the ice shaver conditions exhibited more variability than the super-cooled liquid spray conditions, as expected. For some reason, shaver condition 3 exhibited more variability than the other shaver conditions. 


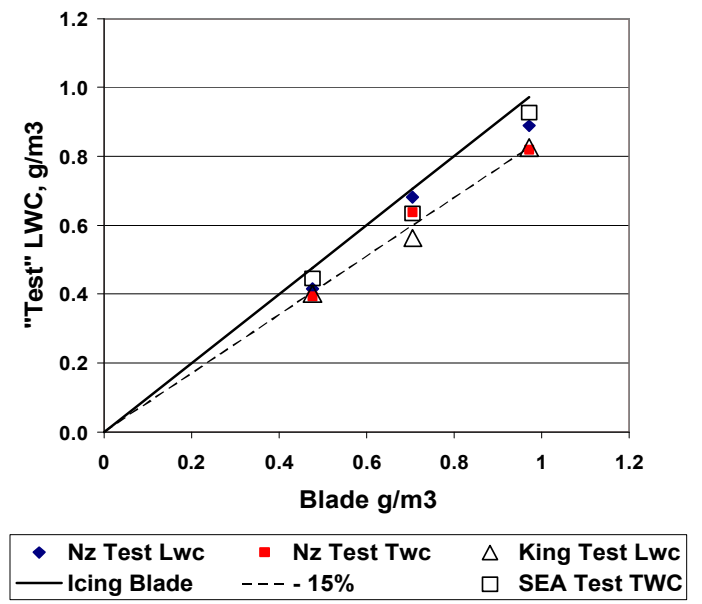

Figure 20. Liquid water content measurements compared to icing blade.

\section{Liquid Water Content Measurements}

Hot-wire probe measurements in super-cooled liquid spray conditions are shown plotted versus the icing blade in Figure 20. Generally speaking, the hot-wire probes as a group tended to indicate a lower LWC than the icing blade.

A line denoting sensor output $15 \%$ below the icing blade is shown in Figure 20 to illustrate that (except for the King probe) the hot-wire probes were within $15 \%$ of the icing blade LWC values. This was considered acceptable based on the fact that practical estimates of hot-wire probe accuracy tend to be on the order of $15 \%$. Also, tests with the King probe and Nevzorov probes in other icing tunnels showed a similar trend. This result gave us confidence that the probes were functioning properly, and provided a baseline response in known conditions.

We were surprised by the King probes relatively low indicated LWC values. Early in the test, we noted that the sense wire had become contaminated with some kind of film. We were unable to remove the film during the test. Though we can't say for certain, we thought this film might provide a possible explanation for the King's lower indicated LWC.

\section{Ice Water Content Measurements}

Ice water content measurements were also obtained in simulated glaciated icing conditions. The Cox \& Company ice shaver was used to generate ice particles for the four glaciated or "all ice" conditions used in this test. Figure 21 shows some typical ice particle images obtained with an OAP-2D grey probe. The particles tended to have irregular shapes and range in size from

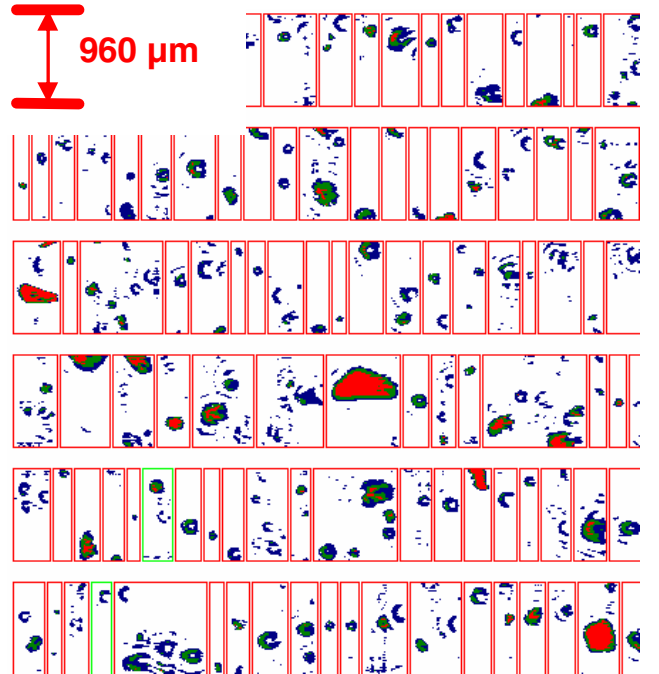

Figure 21. Typical OAP-2D grey probe images of ice shaver particles.

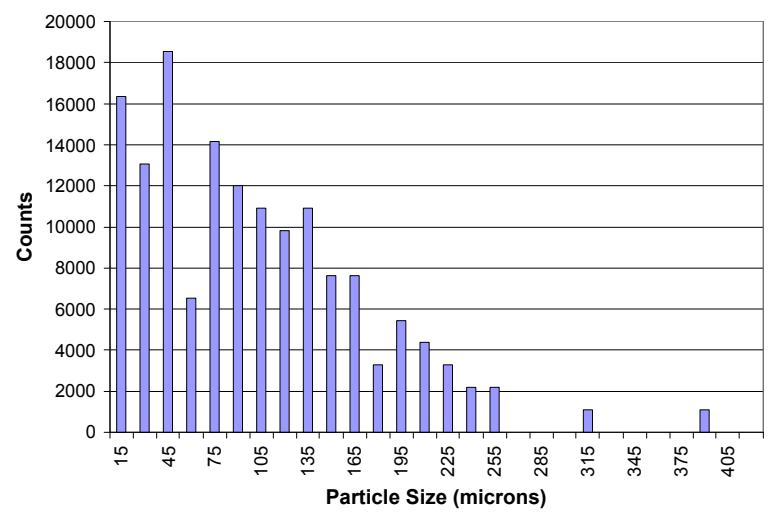

Figure 22. Histogram of ice particle size.

15 to $400 \mu \mathrm{m}$, with the majority of the particles between 100 and $250 \mu \mathrm{m}$. A histogram of ice particle size obtained using the 2D grey probe is shown in Figure 22. We felt that the data in Figure 22 provide a good first order estimate of the size distribution of ice particles used in this experimental investigation. Further analysis will be done with the 2D grey data and FSSP data to get a complete ice particle spectra at a later date.

IWC measurements were obtained from the hot-wire probes for each of the four ice shaver test conditions. The ice shaver was operated continuously for 2 to 4 minutes during a typical test run. Hot-wire sensor measurements were acquired for each test run. An IWC was then calculated for each ice shaver run by averaging the hot-wire sensor output over a 1 minute period within each run. These IWC values from each run were then combined to develop an average IWC for each sensor. 


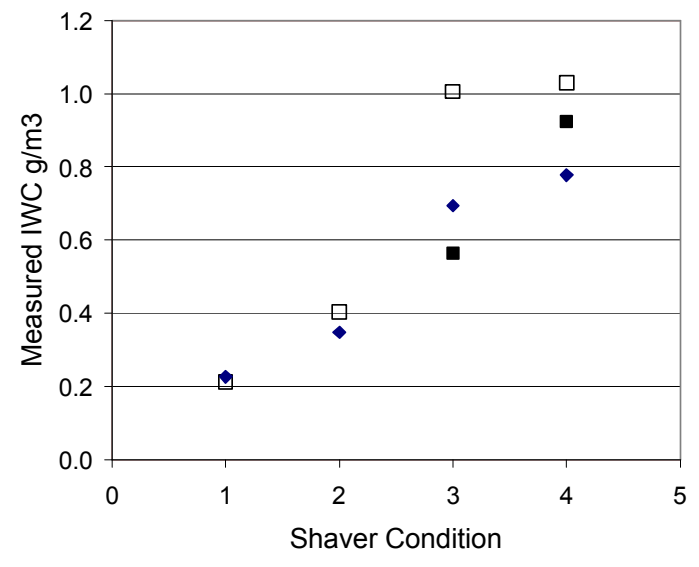

$\square$ Nz Test Twc $\square$ Sea Twc $\bullet$ Nz Ref Twc

Figure 23. Ice water content measurements.

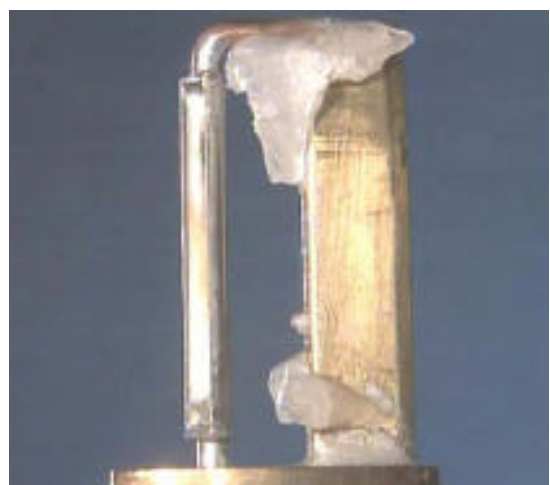

Figure 24. Ice formation on SEA TWC support.

A comparison of average IWC measurements from the Nevzorov and SEA TWC sensors is shown in Figure 23 for each ice shaver condition. In general, the data followed the expected trend of increased IWC with increasing shaver condition number. The IWC indicated by the reference and test Nevzorov TWC sensors appeared to agree within the limits of ice shaver variability shown in Figure 19. TWC measurements with the Nevzorov sensor in the test position were not available for ice shaver conditions 1 and 2 .

Indicated IWC measurements from the SEA TWC sensor are plotted as open squares in Figure 23. Except for condition 3, the IWC indicated by the SEA TWC sensor follows the same trend as the Nevzorov TWC sensors. However, there was a significant difference between the SEA TWC and the Nevzorov TWC values for ice shaver condition 3. An evaluation of HD video imagery indicated that ice was bridging from the rear support structure toward the SEA TWC sensor element.

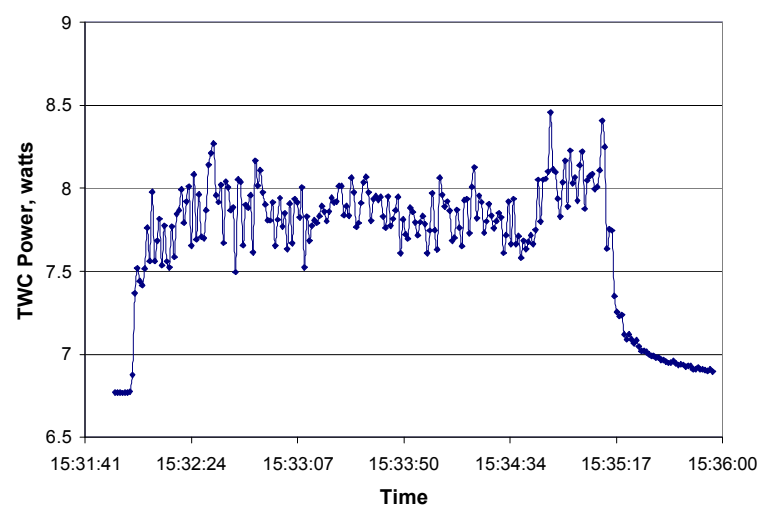

Figure 25. Measured Nevzorov TWC power for ice shaver condition 4 (run 16).

In some cases ice was actually observed to form at the upper and lower ends of the sensor element on the copper support wire as pictured in Figure 24.

We have speculated that this "ice bridging" may have acted as a thermal sink, requiring the SEA TWC sensor control system to supply an additional amount of thermal power to offset this "apparent" thermal load.

The indicated IWC values plotted in Figure 23 are believed to be lower than the actual IWC, based on visual imagery from the HD video and high frame rate cameras. It is likely that the "bouncing" of ice particles and fragments, and the mass ejected from the TWC sensor cone could result in less impinging ice mass, and thereby lead to a lower indicated value of IWC. It is not possible to determine the validity of this statement because no "reference standard" ice measurement was available to compare against. Thus we did not know what the "true" IWC value should have been.

We tried to correlate HD video imagery with Nevzorov TWC power measurements, thinking we might be able to correlate a change in the measured power with the occurrence of pooling. Unfortunately, the time code on the HD video camera was slightly different from that of the data acquisition system. Given the high degree of variability in the measured TWC power signal (Figure 25), we were unable to make conclusive correlation with visual imagery.

In future tests of this nature we intend to broadcast a common time code to the camera systems, and to the data system. In addition, we would like to acquire data at a higher sampling rate to better compensate for the variability in the Nevzorov voltage, current, an power measurements. 


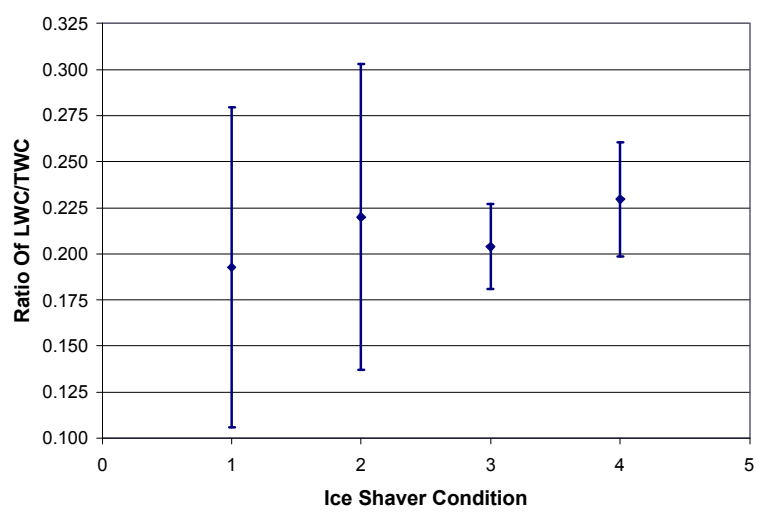

Figure 26. Ratio of indicated IWC from Nevzorov LWC sensor to indicated IWC from TWC sensor.

It is well known that LWC sensors very significantly underestimate IWC in glaciated conditions. Figure 26 shows a plot of the ratio of Nevzorov LWC sensor IWC to TWC sensor IWC. These data were acquired from the Nevzorov probe located in the "reference" position at an airspeed of $67 \mathrm{mps}$, and were representative of the results obtained with the Nevzorov probe located in the "test" position. They are presented here to illustrate that hot-wire LWC probes do have a response to ice particles. This fact has been noted by other researchers such as Korolev, and Strapp. ${ }^{3,4}$ It is believed that this somewhat reduced response to ice particles is due to the heat removed from the sensor element as a result of ice particle collisions. High frame rate camera imagery from this test indicated that small pieces of residual ice remained on the sensing element surface, after an ice particle collision. This visual evidence would seem to support the current explanation for the hot-wire LWC response to ice particles.

The mean value of this ratio is denoted by the marker, while the error bars denote 1 standard deviation about the mean. The mean values of this ratio of TWC/LWC ranged from 0.19 to 0.23 for the conditions of this test. They are somewhat higher than the value of 0.11 estimated by Korolev, using Nevzorov probe flight data obtained in glaciated conditions at an airspeed of $100 \mathrm{mps}^{3}{ }^{3}$ This variation in LWC/TWC ratio may be due to the difference in simulated versus natural ice particle characteristics, among other factors. Because the data set used to generate Figure 26 was somewhat limited due to time constraints, it would be desirable to obtain more data points at each ice shaver condition to verify these results.

\section{SUMMARY AND CONCLUSIONS}

- Three different hot-wire water content sensors were evaluated in a mixed phase icing environment, for the purpose of evaluating their response (measurement performance) to ice particles.

- Ice particles were observed to impact, break up, and bounce off the surface of the sensing elements of all the probes, whereupon they were swept away by the airflow. This was observed to occur whenever ice particles were present in the icing tunnel cloud.

- A preliminary visual analysis to quantify the effect of ice particle "bouncing" on indicated water content measurements was unsuccessful. We plan to investigate other methods for quantifying the effect of "bouncing".

- An unexpected phenomenon, that we labeled "pooling", was observed on the Nevzorov TWC sensor in $100 \%$ ice conditions. The phenomenon resulted in the "pooling" of partially melted ice in the cone of the TWC sensor, before it was eventually expelled into the airflow.

- "Pooling" occurred periodically on the Nevzorov TWC sensor throughout the test runs with $100 \%$ ice, and preliminary results suggest it may be occurring on the SEA TWC, but to a lesser degree. HD video imagery suggested that the occurrence of "pooling" may be related to the level of IWC. Additional testing at lower IWC levels is needed to have more confidence in the validity of this observation.

- Variation of Nevzorov TWC operating temperature did not seem to have a significant effect on the occurrence of "pooling", but future tests at lower IWC levels are needed to better define the relationship between wire temperature and "pooling".

The results presented in this paper are considered a preliminary effort to understand ice particle impact on hot-wire sensor response. It is recognized that additional, more detailed tests are needed to characterize and quantify the response of hot-wire probes to ice particles. 


\section{REFERENCES}

1. Al-Khalil, K., Irani, E., Miller, D., Mixed Phase Icing Simulation and Testing at the Cox Icing Wind Tunnel, 41st AIAA Aerospace Sciences Meeting \& Exhibit, Jan. 2003, AIAA-2003-0903.

2. Korolev, A.V., Strapp, J.W. , Isaac, G.A., Cober, Nevzorov, A.N., The Nevzorov Hot-Wire LWCTWC Probe: Principle of Operation and Performance Characteristic, Journal of Atmospheric and Oceanic Technology, Vol. 15, No. 6, Dec. 1998, pp. 1495-1510.
3. Korolev, A.V., Strapp, J.W., Accuracy of Cloud Ice Water Content by the Nevzorov Probe, 40th AIAA Aerospace Sciences Meeting \& Exhibit, Jan. 2002, AIAA-2002-0679.

4. Strapp, J.W., Chow, P., Moltby, M., Beezer, A.D., Korolev, A.V., Stronberg, I., Hallett, J., Cloud Microphysical Measurements in Thunderstorm Outflow Regions During Allied/BAE 1997 Flight Trials, 37th AIAA Aerospace Sciences Meeting \& Exhibit, Jan. 1999, AIAA-1999-0498. 
Public reporting burden for this collection of information is estimated to average 1 hour per response, including the time for reviewing instructions, searching existing data sources, gathering and maintaining the data needed, and completing and reviewing the collection of information. Send comments regarding this burden estimate or any other aspect of this collection of information, including suggestions for reducing this burden, to Washington Headquarters Services, Directorate for Information Operations and Reports, 1215 Jefferson Davis Highway, Suite 1204, Arlington, VA 22202-4302, and to the Office of Management and Budget, Paperwork Reduction Project (0704-0188), Washington, DC 20503.

\begin{tabular}{|l|l|l}
\hline 1. AGENCY USE ONLY (Leave blank) & $\begin{array}{c}\text { 2. REPORT DATE } \\
\text { March } 2004\end{array}$ & $\begin{array}{r}\text { 3. REPORT TYPE AND DATES COVERED } \\
\text { Technical Memorandum }\end{array}$ \\
\hline
\end{tabular}

\section{TITLE AND SUBTITLE}

Ice Particle Impact on Cloud Water Content Instrumentation

\section{AUTHOR(S)}

Edward F. Emery, Dean R. Miller, Stephen R. Plaskon, Walter Strapp, and Lyle Lillie

\section{PERFORMING ORGANIZATION NAME(S) AND ADDRESS(ES)}

National Aeronautics and Space Administration

John H. Glenn Research Center at Lewis Field

Cleveland, Ohio 44135-3191

\section{FUNDING NUMBERS}

WBS-22-728-41-15

8. PERFORMING ORGANIZATION REPORT NUMBER

E-14437

\section{SPONSORING/MONITORING AGENCY NAME(S) AND ADDRESS(ES)}

National Aeronautics and Space Administration

Washington, DC 20546-0001

10. SPONSORING/MONITORING AGENCY REPORT NUMBER

NASA TM-2004-212964

AIAA-2004-0731

\section{SUPPLEMENTARY NOTES}

Prepared for the 42nd Aerospace Sciences Meeting and Exhibit sponsored by the American Institute of Aeronautics and Astronautics, Reno, Nevada, January 5-8, 2004. Edward F. Emery, Dean R. Miller, and Stephen R. Plaskon, NASA Glenn Research Center; Walter Strapp, Meteorological Services of Canada, Downsview, Ontario M3H5T4; and Lyle Lillie, Science Engineering Associates, Inc., Mansfield Center, Connecticut 06250. Responsible person, Edward F. Emery, organization code 7040, 216-433-5694.

12a. DISTRIBUTION/AVAILABILITY STATEMENT 12b. DISTRIBUTION CODE

Unclassified - Unlimited

Subject Category: 35

Distribution: Nonstandard

Available electronically at http://gltrs.grc.nasa.gov

This publication is available from the NASA Center for AeroSpace Information, 301-621-0390.

\section{ABSTRACT (Maximum 200 words)}

Determining the total amount of water contained in an icing cloud necessitates the measurement of both the liquid droplets and ice particles. One commonly accepted method for measuring cloud water content utilizes a hot wire sensing element, which is maintained at a constant temperature. In this approach, the cloud water content is equated with the power required to keep the sense element at a constant temperature. This method inherently assumes that impinging cloud particles remain on the sensing element surface long enough to be evaporated. In the case of ice particles, this assumption requires that the particles do not bounce off the surface after impact. Recent tests aimed at characterizing ice particle impact on a thermally heated wing section, have raised questions about the validity of this assumption. Ice particles were observed to bounce off the heated wing section a very high percentage of the time. This result could have implications for Total Water Content sensors which are designed to capture ice particles, and thus do not account for bouncing or breakup of ice particles. Based on these results, a test was conducted to investigate ice particle impact on the sensing elements of the following hot-wire cloud water content probes: (1) Nevzorov Total Water Content (TWC)/Liquid Water Content (LWC) probe, (2) Science Engineering Associates TWC probe, and (3) Particle Measuring Systems King probe. Close-up video imaging was used to study ice particle impact on the sensing element of each probe. The measured water content from each probe was also determined for each cloud condition. This paper will present results from this investigation and attempt to evaluate the significance of ice particle impact on hot-wire cloud water content measurements.

\section{SUBJECT TERMS}

Cloud physics 15. NUMBER OF PAGES

$$
\text { Cloud physics }
$$

17. SECURITY CLASSIFICATION OF REPORT

Unclassified

\section{SECURITY CLASSIFICATION OF THIS PAGE \\ Unclassified}

\begin{tabular}{l}
$\begin{array}{l}\text { 19. SECURITY CLASSIFICATION } \\
\text { OF ABSTRACT } \\
\text { Unclassified }\end{array}$ \\
\hline
\end{tabular}

Standard Form 298 (Rev. 2-89)

Prescribed by ANSI Std. Z39-18 298-102 